Rabaska

Revue d'ethnologie de l'Amérique française

\title{
Les Archives acadiennes / Acadian Archives (Université du Maine à Fort-Kent)
}

\section{Lise Pelletier}

Volume 16, 2018

URI : https://id.erudit.org/iderudit/1051378ar

DOI : https://doi.org/10.7202/1051378ar

Aller au sommaire du numéro

Éditeur(s)

Société québécoise d'ethnologie

ISSN

1703-7433 (imprimé)

1916-7350 (numérique)

Découvrir la revue

Citer ce document

Pelletier, L. (2018). Les Archives acadiennes / Acadian Archives (Université du Maine à Fort-Kent). Rabaska, 16, 360-361. https://doi.org/10.7202/1051378ar d'utilisation que vous pouvez consulter en ligne.

https://apropos.erudit.org/fr/usagers/politique-dutilisation/ 


\section{ÉTATS-UNIS}

\section{Les Archives acadiennes / Acadian Archives}

Université du Maine à Fort-Kent

Promenade University

Fort-Kent, Maine

ME 04743
Téléphone : (207) 834-7536 23

Télécopieur : (207) 834-7827

Courriel : acadian@maine.edu

Toile : www.umfk.edu/archives

\section{Acquisitions}

Les collections des Archives acadiennes se sont enrichies dernièrement de nombreux documents : six albums de photographies et d'articles de journaux de Fort-Kent depuis les soixante dernières années déposés par le chiropraticien Marc Chassé, de Fort-Kent ; les registres de la paroisse de Saint-Basile, N.-B. ; des entretiens avec Robert Daigle ; un album de mémoires de l'Association des amis de l'hôpital Northern Maine Medical Center de Fort-Kent; des images recueillies par Frank Soder, agent des services frontaliers (Fort-Kent) des États-Unis ; des images d'Odile Ouellette ; l'uniforme d'un soldat de « La Compagnie Franche de la Marine » (reproduction et recherche); de documents de la famille Paul D. Thibodeau, du père Normand Ludger Thibodeau et de Théodore Paillard ; d'une pièce de lin tissé ; de la correspondance entre Fr. Joseph Marcoux et Aimé Giguère ; de photographies de Paul Cyr ; de manuscrits de recherche et dissertation de Doris Voisine Metz; et d'une collection de photographies de la Société historique de Fort-Kent.

Les Archives acadiennes ont aussi acquis plusieurs romans français du Québec, du Nouveau-Brunswick, de la Nouvelle-Écosse et de la Louisiane; ainsi que plusieurs romans anglais et français d'auteurs franco-américains.

\section{Consultations, communications et collaborations}

Nous continuons d'offrir nos services d'aide en recherches généalogiques, particulièrement axés sur les racines des Acadiens et des Québécois du Québec, du Nouveau-Brunswick, du Maine, de la Nouvelle-Angleterre et même d'ailleurs aux États-Unis.

Également, la directrice des archives a contribué à la recherche du professeur Michael Hillard, de l'Université du Southern Maine, à propos d'une grève à l'usine Fraser de Madawaska, Maine, en 1971 : «Madawaska Rebellion: The 1971 Fraser Paper Mill Strike »); voir mainepublic.org/post/listen-story-strike-fraserpaper\#stream/0. La grève, longue de onze semaines, opposait les Francophones de la vallée du haut Saint-Jean et leurs cadres, des unilingues anglophones. Malgré la présence de policiers, les grévistes ont tenu bon. Même si les salaires ont très peu augmenté, les relations entre Anglophones et Francophones ont complètement changé après cette grève.

Nous poursuivons un projet de préservation avec le Conseil d'héritage acadien du Maine. Un octroi de 20000 dollars permettra aux onze sociétés historiques de la Vallée du fleuve Saint-Jean de numériser leurs collections de documents et de photographies pour ensuite les conserver dans des albums archivistiques. 
Nous avons contribué à la réalisation du documentaire «Acadians of the St. John Valley ». La directrice, $\mathrm{M}^{\mathrm{me}}$ Lise Pelletier, a participé à une émission de radio de la chaîne MPBN, "Maine Calling 》. Cette émission d'une heure portait sur l'effet du 11 septembre et ses suites sur les relations transfrontalières entre le Maine et le Canada. Radio-Canada a aussi eu recours à l'expertise de la directrice pour un reportage sur l'appartenance des Franco-Américains au Canada, la mère patrie de leurs grands-parents.

\section{Expositions}

Trois grandes expositions ont été montées par les Archives acadiennes ; elles portent sur les cartes anciennes du père Jacques LaPointe ; Kekkom de l'artiste malécite Ginette Aubin ; et Évangéline, le personnage, le mythe et la vraie histoire des Acadiens, en salle jusqu'en décembre 2018. Par la suite, cette exposition deviendra itinérante à travers les campus de l'Université de Maine et des États de la NouvelleAngleterre.

\section{Rayonnement}

La directrice a donné un cours de quinze heures intitulé « L'histoire de l'Acadie et des Acadiens du Maine » au semestre d'hiver 2018. Le cours était offert en classe et en ligne. Vingt-trois participants s'y sont inscrits. Un autre cours selon le même format est prévu pour la communauté franco-américaine cet automne : « Le français, langue d'héritage ».

Lise Pelletier

\section{L'Institut français}

Assumption College

500 Salisbury Street

Worcester, Massachusetts

MA 01609-1296
Téléphone : (508) 767-7415 (directrice)

(508) 767-7495 (bibliothécaire)

Courriel : instfran@assumption.edu

Toile : www.assumption.edu/french-institute

L'Institut français est à la fois un établissement de recherches universitaires et un centre d'activités culturelles françaises. Créé en 1979, il perpétue la mémoire de l'héritage francophone du collège de l'Assomption, institution fondée en 1904 par les Augustins de l'Assomption pour desservir la population d'origine canadiennefrançaise. Le but principal de l'Institut est d'encourager la préservation et l'étude de l'histoire et des traditions culturelles de la population francophone en Amérique du Nord, en commençant par la Nouvelle-Angleterre. Comme centre de recherches, l'Institut français acquiert des livres, des archives et des artéfacts pertinents à sa mission primaire. Entre 2004 et 2014, la collection de l'Institut s'est enrichie par l'arrivée sur le campus de la Bibliothèque Mallet et des archives de l'Union SaintJean-Baptiste d'Amérique (UsJB), une société franco-américaine de secours mutuel. Les fonds de l’UsjB sont axés à la fois sur les Français en Amérique du Nord, les Franco-Américains et les Amérindiens. Grâce à ces collections, l'Institut français 